VZŤAH MEDZI DOSIAHNUTÝM VZDELANÍM SESTIER A ICH POSTOJMI K SMRTI

\title{
RELATION BETWEEN NURSING EDUCATION AND ATTITUDES OF NURSES TOWARD DEATH
}

Jana Slováková

Univerzita Komenského v Bratislave, Jesseniova lekárska fakulta v Martine, Ústav ošetrovatel'stva

\section{Abstrakt}

Ciel: V práci sme sa zameriavali na zistovanie postojov sestier $\mathrm{k}$ smrti vo vztahu k vzdelaniu. Chceli sme zistit aké postoje $k$ smrti sestry vo vzt’ahu k vzdelaniu zaujímajú a či medzi týmito skupinami sestier existujú signifikantné rozdiely.

Metódy: Pre zber výskumných údajov sme použili dotazník "Death Attitude Profile - Revised". Výsledky sme vyhodnocovali u piatich skupín sestier, rozdelených podla dosiahnutého vzdelania - SzŠ, VOŠ, BC., Mgr., Iné.

Výsledky: Na základe analýzy získaných údajov sme zistili, že V celom súbore sestier bol najmenej zastúpený postoj strach zo smrti a najviac preferovaný sestrami bol neutrálny postoj. Štatisticky významné rozdiely sme zistili v preferencii postojov vyhýbanie sa smrti, zmierenie sa so smrtou a prijatie smrti vykúpením. Sestry s dosiahnutým vzdelaním (SzŠ, voš, BC.) skôr preferovali vo svojich odpovediach postoj vyhýbanie sa smrti, pričom sestry s magisterským vzdelaním ho preferovali menej. Sestry so vzdelaním (SZŠ, VOŠ, BC.) skôr preferovali vo svojich odpovediach postoj zmierenie sa so smrtou, sestry s magisterským vzdelaním tento postoj preferovali menej. Sestry s dosiahnutým vzdelaním (SzŠ, 
VOŠ)viac preferovali vo svojich odpovediach postoj prijatie smrti vykúpením a sestry $s$ BC. a Mgr. vzdelaním preferovali tento postoj menej.

záver: Na základe našich výsledkov by sme mohli skonštatovat, že dosiahnuté vzdelanie môže mat’ vplyv na vytváranie a formovanie postojov u sestier.

\section{Klúčové slová}

postoje k smrti, sestry, Death Attitude Profile - Revised, dosiahnuté vzdelanie

\section{Key words}

Attitudes Toward Death, Nurses, Death Attitude Profile Revised, Educational Attainment

\section{Abstract}

Aim: The main aim is to examine attitudes of nurses toward death in relation to educational attainment and also to examine significant differences in preference of these attitudes between groups of nurses divided by educational attainment.

Methods: We used as research instrument "Death Attitudes Profile - Revised" in our research.

Results: We evaluated results in five groups of nurses, broken down by educational attainment - Hight school for nursing, Higher education in nursing, Bachelor's degree, Master's degree, Other's degree - specialization in nursing. On the basis of analyzing the data, we found that in the whole sample of nurses was at least represented attitude - Fear of death and the most preferred was a Neutral acceptance. An exception formed the group of nurses with other levels of education, which most preferred attitude of Escape 
acceptance. Statistically significant differences seen in the attitudes of Death avoidance, Approach acceptance and Escape acceptance. Nurses with educational attainment (Hight school for nursing, Higher education in nursing, Bachelor's degree) more prefer the attitude of avoiding death, while nurses with Master's degree prefer this attitude less. Nurse education (Hight school for nursing, Higher education in nursing, Bachelor's degree) more prefer the attitude of approach acceptance, nurses with Master's degree this attitude prefer less. Nurses with educational attainment (Hight school for nursing, Higher education in nursing) more prefer the attitude Escape acceptance while nurses with Bachelor and Master's degree of nursing prefer this attitude less.

Conclusion: Based on our results we could note that there is clearly demonstrated the impact of education in shaping attitudes in nurses.

\section{Úvod}

Mnohí autori v zahraničí vo svojich prácach(napr. Knight, Elfenbein, 1993, Was, 2004) poukázali na pozitívny vplyv vzdelávania na vytváranie a formovanie postojov. Existujú však aj výskumy, v ktorých tento vplyv dokázaný nebol napr. Rooda, Clements, Jordan, 1999). V spomínaných prácach boli cielovou skupinou sestry, ktoré v rámci svojej profesie môžu prichádzat do kontaktu s umieraním a smrtiou pomerne často alebo študenti dennej formy štúdia $v$ odbore ošetrovatel'stvo (napr. Wong et al., 1994, Rooda et al., 1999, Weiler, 2001, Dunn et al., 2005, Wessel, Rutledge, 2005). V týchto štúdiách sa skúmal nielen vplyv dosiahnutého vzdelania sestier, ale konkrétne vplyv vzdelávania $v$ oblasti smrti a umierania resp. 
paliativnej starostlivosti na vytváranie, formovanie či zmeny postojov $k$ smrti a umieraniu u sestier. V našich podmienkach nie je možné skúmat vplyv tohto druhu vzdelávania, pretože u nás takáto forma vzdelávania ani edukačných programov, či kurzov neexistuje. V našej práci sme sa preto rozhodli skúmat vplyv dosiahnutého vzdelania u sestier (SzŠ, VOŠ, BC., Mgr., Iné $\left.{ }^{1}\right)$ na postoje $\mathrm{k}$ smrti, pričom sme vychádzali z predpokladu, že úroveň poskytnutých informácií v oblasti smrti a umierania, resp. paliatívnej starostlivosti je obsiahlejšia v závislosti na dosiahnutom vzdelaní sestier.

\section{Ciel práce}

Cielom práce bolo zistit’ postoje k smrti u sestier, ktoré majú dosiahnuté rozdielne vzdelanie (SzŠ, VOŠ, BC., Mgr., Iné) a aj to, či medzi týmito skupinami sestier existujú štatisticky významné rozdiely $v$ preferencii týchto postojov.

\section{Súbor}

Výskum prebiehal v období máj, jún 2008. Do výskumného súboru boli zaradené sestry pracujúce na oddeleniach dvoch nemocníc: MFN Martin a NsP Trstená. Zadelovacím kritériom do súboru bola ošetrovatelská prax sestier ${ }^{2}$ pri lôžku pacienta a ich ochota vyplnit' dotazník.

Celkový počet respondentiek bol $\mathrm{n}=200, \mathrm{z}$ toho 123 (61,5 \%) respondentiek bolo z MFN Martin a 77 (38,5%) z NsP Trstená. Respondenti boli ženského pohlavia, v priemernom veku $40 \pm$

\footnotetext{
1 Pod označenie "iné" sme zaradili špecializačné štúdium v kategórii sestra. V tejto skupine bolo sedem sestier, $n=7$. Napriek tomu, že v tejto skupine sestier boli zistené signifikantné rozdiely v preferencii postojov (prijatie smrti vykúpením $x=5,60 \pm 0,55$, zmierenie sa so smrtiou $x=5,04 \pm 0,73$, neutrálny postoj $x=5,60 \pm 0,73$, vyhýbanie sa smrti $x=4,65 \pm 1,34$, strach zo smrti $x=3,59 \pm 1,30)$ v porovnaní s inými skupinami sestier podla dosiahnutého vzdelania, pokladáme tieto výsledky z hladiska velkosti skupiny sestier za irelevantné. (pozn. autorky)

2 Ošetrovatel'ská prax sestier nebola ohraničená počtom rokov praxe
} 
9,49 rokov. Najviac zastúpený počet rokov praxe bol viac ako 25 rokov ( $\mathrm{n}=61,30,5 \%$ ) a najmenej $0-2$ roky praxe ( $\mathrm{n}=16$, 8\%). Náboženskú vieru uvádzalo 164 (82 \%) sestier, 36 (18\%) sestier náboženskú vieru neuvádzalo. Z celého súboru sestier, $60(30$ \%) sestier udávalo dosiahnuté stredoškolské vzdelanie, $77(38,5$ \%) sestier - vyššie odborné štúdium, 34 (17 \%) sestier - bakalársky stupeň vzdelania, 22 (11 \%) sestier magisterský stupeň a 7 (3,5%) sestier - iný stupeň vzdelania.

\section{Metodika}

Pre zber údajov sme použili dotazník Death Attitude Profile Revised. (Wong et al., 1994, s. $147-148)^{3}$ DAP - R je 32 položkový multidimenzionálny merací nástroj s Likertovou škálou od 1 (úplne nesúhlasím) do 7 (úplne súhlasím). Pozostáva z piatich dimenzií. Prvou dimenziou je strach zo smrti (sedem položiek), ktorá meria negatívne myšlienky a pocity o smrti. Druhou dimenziou je vyhýbanie sa smrti (pät položiek), ktorá meria pokusy vyhýbat sa myšlienkam na smrt̉. Neutrálna akceptácia (pät položiek) je tretia dimenzia, ktorá meria rozsah, v ktorom človek akceptuje smrt' ako realitu neutrálnym spôsobom. Človek vidí smrt’ ako prirodzenú súčast’ života a akceptuje ju ako nevyhnutný fakt života bez strachu. Zmierenie sa so smrtou (desat položiek) je štvrtou dimenziou, ktorá meria rozsah, v ktorom Človek vidí smrt’ ako vstup k šṫastnému posmrtnému životu. Piatou dimenziou je prijatie smrti vykúpením (pät položiek), ktorá meria rozsah, v ktorom vidí človek smrț ako ponúkanú možnost' uniknút od bolesti a utrpenia. (Wessel, Rutledge, 2005, s. 214; Wong et al., 1994, s. 148; Weiler, 2001, s. 83)

3 DAP-R je upravenou verziou Death Attitude Profile (DAP), ktorý bol prvým dotazníkom zaoberajúcim sa problematikou smrti a umierania vo vzt’ahu $\mathrm{k}$ postojom. Obsahoval dimenzie strach zo smrti a umierania, Prijatie smrti vykúpením, Zmierenie sa so smrtoou, Neutrálna akceptácia. 
Získané údaje sú spracované metódou opisnej štatistiky. Bola určená priemerná škálová hodnota odpovedí $(\bar{x}$ - aritmetický priemer), variabilita odpovedí (SD - štandardná odchýlka). Na zistenie štatisticky významných rozdielov boli použité testy MANOVA, ANOVA.

\section{Výsledky}

V nasledujúcich tabul'kách (Tab. 1,2,3) sú znázornené údaje získané vo výskume.

Tab. 1 Preferencie postojov u sestier podla vzdelania

\begin{tabular}{|c|c|c|c|c|c|c|c|c|c|c|c|}
\hline \multirow{2}{*}{\multicolumn{2}{|c|}{ Vzdelanie }} & \multicolumn{2}{|c|}{ SzŠ $n=60$} & \multicolumn{2}{|c|}{ voš $n=77$} & \multicolumn{2}{|c|}{ BC. $n=34$} & \multicolumn{2}{|c|}{ Mgr. $n=22$} & \multicolumn{2}{|c|}{ Iný. $n=7$} \\
\hline & & $\mathbf{x}$ & SD & $\mathbf{x}$ & SD & $\mathrm{x}$ & SD & $\mathbf{x}$ & SD & $\mathrm{x}$ & SD \\
\hline \multirow{8}{*}{$\begin{array}{l}\text { Poradie } \\
\text { postojov }\end{array}$} & \multirow{3}{*}{$\begin{array}{l}1 . \\
2 .\end{array}$} & \multicolumn{2}{|c|}{$\begin{array}{l}\text { Neutrálna } \\
\text { akceptácia }\end{array}$} & \multicolumn{2}{|c|}{$\begin{array}{l}\text { Neutrálna } \\
\text { akceptácia }\end{array}$} & \multicolumn{2}{|c|}{$\begin{array}{l}\text { Neutrálna } \\
\text { akceptácia }\end{array}$} & \multicolumn{2}{|c|}{$\begin{array}{l}\text { Neutrálna } \\
\text { akceptácia }\end{array}$} & \multicolumn{2}{|c|}{$\begin{array}{l}\text { Prijatie smrti } \\
\text { vykúpením }\end{array}$} \\
\hline & & 5,65 & 0,71 & 5,66 & 5,92 & 1,36 & 0,71 & 5,58 & 0,86 & 5,04 & 0,73 \\
\hline & & \multicolumn{2}{|c|}{$\begin{array}{l}\text { Prijatie smrti } \\
\text { vykúpením }\end{array}$} & \multicolumn{2}{|c|}{$\begin{array}{l}\text { Vyhýbanie sa } \\
\text { smrti }\end{array}$} & \multicolumn{2}{|c|}{$\begin{array}{l}\text { Zmierenie } \\
\text { sa so smrt'ou }\end{array}$} & \multicolumn{2}{|c|}{$\begin{array}{l}\text { Vyhýbanie sa } \\
\text { smrti }\end{array}$} & \multicolumn{2}{|c|}{$\begin{array}{l}\text { Zmierenie } \\
\text { sa so smrtoou }\end{array}$} \\
\hline & \multirow{3}{*}{3.} & 5,08 & 1,19 & 4,99 & 4,09 & 1,63 & 1,24 & 4,50 & 1,09 & 5,60 & 0,55 \\
\hline & & \multicolumn{2}{|c|}{$\begin{array}{l}\text { Vyhýbanie sa } \\
\text { smrti }\end{array}$} & \multicolumn{2}{|c|}{$\begin{array}{l}\text { Prijatie smrti } \\
\text { vykúpením }\end{array}$} & \multicolumn{2}{|c|}{$\begin{array}{l}\text { Vyhýbanie sa } \\
\text { smrti }\end{array}$} & \multicolumn{2}{|c|}{$\begin{array}{l}\text { Prijatie smrti } \\
\text { vykúpením }\end{array}$} & \multicolumn{2}{|c|}{$\begin{array}{l}\text { Neutrálna } \\
\text { akceptácia }\end{array}$} \\
\hline & & 4,92 & 1,39 & 4,84 & 3,8 & 1,49 & 1,29 & 4,44 & 1,43 & 5,00 & 0,73 \\
\hline & \multirow[t]{2}{*}{4.} & \multicolumn{2}{|c|}{$\begin{array}{l}\text { Zmierenie } \\
\text { sa so smrťou }\end{array}$} & \multicolumn{2}{|c|}{$\begin{array}{l}\text { Zmierenie } \\
\text { sa so smrtoou }\end{array}$} & \multicolumn{2}{|c|}{$\begin{array}{l}\text { Prijatie smrti } \\
\text { vykúpením }\end{array}$} & \multicolumn{2}{|c|}{$\begin{array}{l}\text { Zmierenie } \\
\text { sa so smrtiou }\end{array}$} & \multicolumn{2}{|c|}{$\begin{array}{l}\text { Vyhýbanie sa } \\
\text { smrti }\end{array}$} \\
\hline & & 4,13 & 1,24 & 3,89 & 3,39 & 1,25 & 1,16 & 4,23 & 1,03 & 3,59 & 1,30 \\
\hline
\end{tabular}

Z Tab. 1 vyplýva, že $v$ celom súbore sa sestry najmenej stotožn̆ovali s postojom strach zo smrti. Najviac preferovali neutrálnu akceptáciu sestry so vzdelaním (SzŠ, Voš, BC., Mgr.). Postoj vyhýbanie sa smrti bol druhým najpreferovanejším postojom u sestier so stredoškolským vzdelaním a tretím u sestier s bakalárskym vzdelaním. Postoj prijatie smrti vykúpením bol druhým najpreferovanejším postojom u sestier so stredoškolským vzdelaním a tretím u sestier s magisterským vzdelaním. Postoj zmierenie sa so smrtou bol u troch skupín sestier (SZĽ, VOŠ, Mgr.) na štvrtom mieste v preferencii postojov. 
MANOVA testom sme zistiovali, či sú prítomné štatisticky významné rozdiely ${ }^{4}$ v DAP - R vo vzt’ahu $k$ dosiahnutému vzdelaniu (Tab. 2) .

Tab. 2 Overenie štatistických rozdielov $\mathbf{v}$ dimenziách postojov k smrti z hladiska dosiahnutého vzdelania (MANOVA test)

Vzdelanie

\begin{tabular}{|c|c|c|l|c||}
\hline Wilksonova Lambda & $F$ & Hypothesis df. & Error df. & P \\
\hline \hline 0,758 & 2,71 & 20,000 & 621,159 & 0,000 \\
\hline
\end{tabular}

Pomocou ANOVA testu sme overovali, v ktorých dimenziách konkrétne boli signifikantné rozdiely.

Tab. 3 Overenie štatistických rozdielov $v$ dimenziách postojov k smrti z hladiska dosiahnutého vzdelania (ANOVA test)

\begin{tabular}{||l|l|c|c||}
\hline & \multicolumn{1}{|c|}{ Dimenzia } & F & P \\
\hline \hline \multirow{4}{*}{ vzdelanie } & Strach zo smrti & 2,206 & 0,070 \\
\cline { 2 - 4 } & Vyhýbanie sa smrti & $\mathbf{3 , 2 6 9}$ & $\mathbf{0 , 0 1 3}$ \\
\cline { 2 - 4 } & Neutrálna akceptácia & 1,024 & 0,396 \\
\cline { 2 - 4 } & Zmierenie sa so smrt́ou & $\mathbf{2 , 9 6 9}$ & $\mathbf{0 , 0 2 1}$ \\
\cline { 2 - 4 } & Prijatie smrti vykúpením & $\mathbf{4 , 8 9 8}$ & $\mathbf{0 , 0 0 1}$ \\
\hline
\end{tabular}

Hladina významnosti $\mathrm{P}<0,05$ dokazuje, že $\mathrm{v}$ dimenziách vyhýbanie sa smrti, zmierenie sa so smrtiou a prijatie smrti vykúpením existujú signifikantné rozdiely podla vzdelania. Môžeme konštatovat', že sestry so stredoškolským vzdelaním, s vyšším odborným vzdelaním a bakalárskym vzdelaním viac preferovali vo svojich odpovediach postoj vyhýbanie sa smrti (SZ ̌ $\bar{x}=4,92 \pm 1,39$, VOŠ $\bar{x}=4,99 \pm 1,24$, BC. $\bar{x}$ $=4,440 \pm 1,43)$,pričom sestry s magisterským vzdelaním ho preferovali menej $(\bar{x}=4,09 \pm 1,63)$.

\footnotetext{
${ }^{4} \mathrm{Na}$ určenie hladiny významnosti sa používalo tradičných 5 \%, teda P < 0,05 je štatisticky významné, P>=0,05 nie je štatisticky významné.
} 
Sestry so stredoškolským vzdelaním, s vy̌ším odborným vzdelaním a bakalárskym vzdelaním viac preferovali vo svojich odpovediach postoj zmierenie sa so smrtou (szš $\bar{x}$

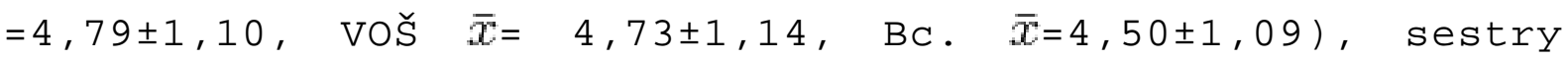
s magisterským vzdelaním ho preferovali menej $(\bar{x}=3,65 \pm$ $1,38)$.

Sestry so stredoškolským vzdelaním, s vyšším odborným vzdelaním viac preferovali vo svojich odpovediach postoj prijatie smrti vykúpením (Sz ̌ $\quad \bar{x}=5,08 \pm 1,19, \operatorname{voš} \quad \bar{x}=$ $4,84 \pm 1,29)$, sestry $\quad$ s bakalárskym $\quad(\bar{x}=4,38 \pm 1,36)$ a magisterským $(\bar{x}=3,8 \pm 1,49)$ vzdelaním preferovali tento postoj menej.

\section{Diskusia}

Prvým cielom práce bolo zistit', aké postoje k smrti majú sestry podla dosiahnutého vzdelania. Z výsledkov výskumu vyplýva, že u všetkých skupín sestier vo vzt̉ahu k dosiahnutému vzdelaniu bol najviac zastúpený neutrálny postoj k smrti, kedy človek vidí smrt’ ako prirodzenú súčast' života a akceptuje ju ako nevyhnutný fakt života bez prítomnosti strachu, čo sa potvrdilo aj menším preferovaním postoja strach zo smrti v našom výskumnom súbore sestier.

V práci Wessel, Rutledge (2005, s. 216) na základe svojich výsledkov zistili, že sestry sa prikláňali viac k pozitívnym postojom $k$ smrti a umieraniu. V tejto práci boli medzi pozitívne postoje zaradené: neutrálny postoj, zmierenie sa so smrtiou a prijatie smrti vykúpením. V d’alšej štúdii autori Dunn, Otten, Stephens (2005, s. 101) tiež zistili, že sestry vidia smrt’ ako realitu a prevláda u nich neutrálna akceptácia, pričom vidia smrt’ ako prirodzený aspekt života a nepovažujú smrt́ ani za dobrú ani za zlú. Pri porovnaní týchto výsledkov 
v spomínaných štúdiách s našimi výsledkami môžeme skonštatovat, že vzdelanie sestier nemusí mat’ vplyv na to, ako sestry smrt' vidia, ako a či sa ňou vôbec zaoberajú.

Postoje k smrti a umieraniu sa vytvárajú v priebehu socializácie v danej spoločnosti, kultúry a dalej sa formujú vplyvom rôznych faktorov, pričom tento proces formovania resp. modulovania postojov k smrti je individuálny. To znamená, že v konečnom dôsledku to závisí od toho, o akú osobnost' Človeka ide. Na druhej strane však nemôžeme jednoznačne povedat', že v tomto prípade nemá vzdelanie vplyv na to, ako sestry smrẗ vidia, ako a či sa ňou vôbec zaoberajú pretože všetky sestry $v$ našom súbore ako aj $v$ iných štúdiách nepovažovali smrt́ ani za dobrú ani za zlú, pokladali ju za neodvratnú udalost̉ v živote každého človeka a nepocitoovali obavy, strach zo smrti a z myšlienok na ňu.

Druhým cielom v našej práci bolo zistit', či medzi jednotlivými skupinami sestier vo vzţahu k dosiahnutému vzdelaniu existujú rozdiely $v$ postojoch $\mathrm{k}$ smrti. Zistili sme, že na základe dosiahnutého vzdelania existujú rozdiely v preferencii postojov vyhýbanie sa smrti, zmierenie sa so smrtoou, prijatie smrti vykúpením. To, že neboli zistené rozdiely v preferencii postojov - strach zo smrti a neutrálna akceptácia môže byt̉ dôsledkom vplyvu viacerých faktorov. Niektorí autori (napr. Wong et al., 1994; Wessel, Rutledge, 2005; Dunn et al., 2005) medzi tieto faktory zahŕňajú minulú skúsenost so smrtiou, náboženskú vieru, dížku ošetrovatel’skej praxe, pohlavie, vek, či absolvovanie špeciálnych edukačných kurzov v oblasti smrti a umierania. V podobných štúdiách, ktoré sa robili v priebehu minulých rokov bolo zistené, že dosiahnuté vzdelanie sestier neovplyvňuje ich postoje k smrti (napr. Rooda et al., 1999, s. 
1686). Avšak autori, ktorí sa zaoberali vplyvom vzdelania $v$ oblasti smrti a umierania na formovanie postojov $k$ smrti (napr. Frommelt, 2003) zistili, že sestry, ktoré absolvovali tento druh vzdelávania ${ }^{5}$ mali viac pozitívne postoje $\mathrm{k}$ smrti a že sestry, ktoré mali vyšší stupeň vzdelania absolvovali viac kurzov vzdelávania v oblasti smrti a umierania ako sestry, ktoré mali nižší stupeň vzdelania. (Dunn et al., 2005, S. 101)

\section{Záver}

Na základe našich výsledkov by sme mohli skonštatovat', že dosiahnuté vzdelanie môže mat' vplyv na vytváranie a formovanie postojov u sestier, pretože sme zistili signifikantné rozdiely v preferencii postojov v závislosti od dosiahnutého vzdelania. Na vytváraní a formovaní postojov k smrti sa možu podielat aj iné faktory. Preto je potrebné pri vytváraní a formovaní konkrétnych postojov k smrti brat’ do úvahy tiež vplyv týchto faktorov, čo môže byt námetom pre budúci výskum v tejto oblasti.

\section{Zoznam bibliografických odkazov}

DUNN, K. S. et al. 2005. Nursing experience and the care of Dying Patients. Oncology Nursing Forum. 2005, vol. 32, no. 1, p. 97-104. ISSN 0190-535X.

GESSER, G. et al. 1987 - 1988. Death Attitudes Across The Life-Span: The Development And Validation of The Death Attitude Profile. Omega : Journal of Death and Dying. 1987 1988, vol. 18, no. 2, p. 113-128. ISSN 0030-2228.

\footnotetext{
5 vzdelávanie v oblasti smrti a umierania, ktoré prebiehalo formou kurzu s dížkou jedného semestra (pozn. autorky)
} 
KNIGHT, K. H., ELFENBEIN, M. H. 2001. Relationship of Death Education to the Anxiety, Fear, and Meaning associated with death. Death Studies. 2001, vol. 17, p. 411-425. ISSN 07481187 .

NEIMEYER, R. A. 1994. Death Anxiety Handbook - Research, Instrumentation and Application. 1. ed. Washington : Taylor \& Francis, 1994. 284 p. ISBN 1-56032-2829.

NEIMEYER, R. A. et al. 2004. Psychological Research on Death Attitudes: An everview and evaluation. Death Studies. 2004, vol. 28, no. 4, p. 309-340. ISSN 0748-1187.

ROODA, L.A. et al. 1999. Nurses' Attitudes Toward Death and Caring for Dying Patients. Research Briefs. 1999, vol. 26, no. 10, p. 1683-1687. ISSN 1832-2883.

WASS, H. 2004. A Perspective on the current state of death education. Death Studies. 2004, vol. 28, p. 289-308. ISSN $0748-1187$.

WEILER, P. D. 2001. Aging with success: Theory of personal meaning as a model of understanding death attitudes. Trinity Western University. 2001. Dissertation. 83 p. WESSEL, M. E., RUTLEDGE, N. D. 2005. Home Care and Hospice Nurses Attitudes Toward Death and Caring for the Dying. Journal of Hospice and Palliative Nursing. 2005, vol. 7, no. 4, p. 212-218. ISSN 1522-2179.

WONG, P. T. P. et al. 1994. Death Attitude profile - Revised: A Multidimensional Measure of Attitudes Toward Death. In NEIMEYeR, R. A. Death Anxiety Handbook - Research, Instrumentation and Application. 1. ed. Washington: Taylor \& Francis, 1994. p. 121-148. ISBN 1-56032-282-9. 


\section{Kontakt na autora:}

Mgr. Jana Slováková

Ústav ošetrovatel'stva JLF UK

Malá Hora 5

SK-036 01 MARTIN

slovakova@jfmed.uniba.sk 